\title{
O analista como detetive selvagem ${ }^{1}$
}

\author{
Mariano Horenstein ${ }^{2}$
}

\section{Um estranho no banquete}

Considero uma honra estar aqui, nesta mesa inaugural do primeiro symposium de uma sociedade que tem tradição o suficiente como para perguntar-se por que começar agora... E me permito fazer essa pergunta porque este é meu lugar aqui, o do estrangeiro. E o estrangeiro, segundo Derrida, é quem traz as perguntas. Derrida também escreveu sobre a hospitalidade com o Outro, o estrangeiro, hospitalidade da qual me beneficio hoje e agradeço com o coração.

Um symposium, um banquete onde certamente não faltará vinho, era o lugar no qual os gregos se juntavam para conversar. O Banquete de Platão é o relato de uma reunião assim. Só que não havia lugar para os estrangeiros ali: quem participava eram os cidadãos. Mas hoje vocês iniciam uma longa cadeia de simpósios com esta marca que celebro, a do alheio, o xenos. O pedido por parte dos organizadores de que fale na minha língua - compreensível talvez, mas também alheia - ao invés de ler em português, não faz senão ratificar o que intuo e celebro.

Embora na verdade não seja o xenos, para sermos precisos, o lugar do analista. Tempo atrás compartilhei um espaço escrito com Márcio onde ele falava justamente desse lugar impossível, topos outopos, a terceira margem do rio segundo Guimarães Rosa, que é o lugar do analista. De minha parte, concordava e propunha - a partir de suas reflexões sobre o oikos, o doméstico- para pensar o lugar do analista na cidade a figura do metoikos.

O meteco era na polis grega um estrangeiro isolado na cidade, alheio ao concerto dos cidadãos, embora não tanto a ponto de não poder escutá-los. Eu não escuto aos habitantes desta cidade, como vocês. Apenas falo aqui como o estrangeiro que usufrui de um acolhimento hospitaleiro.

\footnotetext{
${ }^{1}$ Este trabalho é a plenária do eixo "O analista desconcertado", apresentada no I Simpósio Bienal "O mesmo, o outro: Psicanálise em movimento" eixo "O analista desconcertado: mal estar e cínica” da Sociedade Brasileira de Psicanálise de São Paulo.

2 Analista didata da Sociedade Psicanalítica de Córdoba, ex editor da revista Calibán, recebeu os prêmios Hayman, Bergwerk, Lucien Freud e Á. Garma.
} 
Este banquete paulista começa então dando a palavra a um estranho, e pretendo aproveitá-la. Se o tema daquele symposium mítico era o amor, o deste é o desconcerto.

Ninguém é imune ao desconcerto, mas o que diferencia um analista desconcertado de um médico, um engenheiro desconcertado ou um advogado desconcertado? Esquematicamente, só uma coisa: para qualquer dessas profissões, o desconcerto é um estado geralmente transitório, que impede ou condiciona sua prática e frente à qual o profissional atuará prontamente para resolvê-lo. Para o analista, contrariamente, o desconcerto é um estado necessário que, longe de impossibilitar, talvez habilite o exercício de sua função. Não se trata de um estado a ser evitado, mas de uma posição a ser alcançada e, quem sabe, quanto maior o desconcerto, maior seja a amplitude de sua escuta e a potência de sua intervenção.

\section{Modos de ouvir}

Como um modo de sortear o obstáculo de uma discussão à qual chegamos desde distintos paradigmas teóricos, quero valer-me, para ampliar - e quem sabe, com sorte, esclarecer essa diferença - de um discurso alheio e ao mesmo tempo intimamente ligado ao nosso, o da literatura, "a grande estrangeira", como era chamada por Foucault. E pensar a partir disso na análise como pesquisa e no analista como detetive. E colocar aqui ao desconcerto em uma tríade, em relação ao enigma e ao mistério.

O analista tem sido comparado com um detetive da mente. Não é uma má comparação, sempre e quando se diferenciem modalidades que possam de alguma forma parear-se com a evolução desse gênero literário, o romance policial.

No final do século XIX o gênero estava sendo inventado por Edgar Allan Poe baixo o paradigma do enigma. O detetive de Poe, Arsène Dupin, como o de Arthur C. Doyle, Sherlock Holmes, ou posteriormente o de Agatha Christie, Hércules Poirot, eram personalidades analíticas que se valiam do método dedutivo para desfazer enigmas. O herói resolvia um enigma - um assassinato num quarto fechado ou no Orient Express decodificando indícios em uma tarefa intelectual e asséptica, sem sequer manchar-se.

Paralelamente, quando Freud resolvia seus casos de paralisia, anestesias ou afasias histéricas lendo o sentido cifrado nos sintomas, se encontrava no mesmo paradigma indiciário. Aí Freud - como logo faria Lacan na época em que confiava na primazia do simbólico e na capacidade do analista de decifrar sintomas solucionando charadas linguageiras - exercia uma tarefa detetivesca e arqueológica, identificando-se com Morelli ou Schliemann. 
Escutar implica também um modo de ler: bastava inteligir, lendo, o código encriptado nos sintomas para que estes desapareçam. O enigma era uma charada que - como a esfinge de Sófocles e Freud - convidava sua resolução prometendo um reino a quem o conseguisse.

Só que depois, lamentavelmente, tudo resultou ser mais complexo. Na década de 20 Freud se enfrenta com a clínica da repetição que não lhe permitiu continuar sendo otimista, e que desemboca em uma virada teórica e sua postulação da pulsão de morte. Ao mesmo tempo, na outra margem do mundo, surgia uma nova variante do gênero policial, das mãos de escritores como Raymond Chandler e Dashiel Hammett, criadores de detetives lendários como Philip Marlowe e Sam Spade. Certamente os conhecem a partir de novelas ou filmes: trata-se de figuras prototípicas completamente diferentes de suas antecessoras. Aqui o detetive é um desclassado que trabalha num pântano onde a lei se distingue mal do mundo meliante, e seu lugar é o de verdadeiros marginais que, por sua própria posição social - uma sorte de metecos também - conseguem enxergar o que outros não.

Quem sabe o gênero negro tenha surgido como uma resposta perante os mesmos fenômenos que a renovação teórica freudiana ou sua contraparte lacaniana, que logo após ter sido enfeitiçada pelo simbólico nos anos 50, privilegiou o peso do real, a viscosidade do gozo que empantanava a clínica. Estamos longe do detetive impoluto que se exercitava em uma destreza intelectual, e perto de um marginal que, mesmo com sua ética implacável, desacreditava de toda instituição. Se a imagem anterior era a de um arqueólogo que desenterrava ruínas de cidades ou decifrava, como Champollion, códigos de pedra, a metáfora agora é a de um antropólogo forense que trabalha logo após um massacre que ainda não cessou, resgatando restos nec nomine, adivinhando peças que faltam, restituindo com invenções uma memória perdida.

Se o primeiro modelo de detetive põe o enigmático em cena e a análise como decifração, o segundo modelo realça o mistério (inclusive o mistério do sexual), o ritmo trepidante do thriller e o convívio com os pântanos de uma zona escorregadia onde não chegam nem a lei nem a ordem. Duas clínicas são tributárias destas imagens: a do decifrador das charadas encriptadas em sonhos, sintomas e atos falhos; e a do lutador de catch com as formas do gozo resistentes à interpretação, a clínica das bordas. Embora ambos os modelos se sucedam, também coexistem.

Se do primeiro modelo surge a associação livre como método onde se privilegia o detalhe nímio, a disciplina da pergunta e a interpretação reveladora; do segundo surge a luta 
encarniçada contra o gozo, a inércia da pulsão. Através de ambas as influências, o enigma como forma interpretativa tão afim ao oráculo - e o mistério - esse gancho que prende um analisante, o levando a voltar uma e outra vez - ganham um lugar na nossa prática.

Se o enigma e o mistério têm um lugar na análise e determinam a forma particular da nossa escuta, em troca não a temos para o segredo. O segredo é o que se oculta sabidamente, o subtraído da análise, portanto violação deliberada da regra fundamental. Se antes enfrentávamos modos de ouvir ligados ao detetivesco, com o segredo estamos mais perto da espionagem. $\mathrm{O}$ enigma e o mistério guardam afinidade com a neurose, no entanto no segredo nos encontramos com seu reverso perverso. A escuta do espião, diferentemente das outras, é furtiva e invasora, uma intromissão violenta da qual só podemos esperar o pior. Esta escuta violenta sua própria forma convertendo-se em voyeurística, chusma ${ }^{3}$, perversamente interessada em auscultar a vida dos outros, reedições de uma cena primária ${ }^{4}$.

Perante um espião o que se fala convoca a escuta; em troca, em tom detetivesco é a escuta que produz o falado. Não se trata de ouvir porque alguém fala de algum modo incriminador, mas o oposto, como na análise, de montar um dispositivo de escuta que, em sua hospitalidade, propicie o dizer.

Agora bem, se enigma e mistério, sintoma cifrado e gozo encarnam duas figuras do analista detetive, quem sabe haja uma terceira, mais indefinida, a ser construída, virada para o futuro. Não temos que buscar seus rastros nos autores de policiais, mas nos poetas. Roberto Bolaño publicou uma novela contemporânea que trata "da aventura, que sempre é inesperada". Protagonizada por dois poetas marginais em uma busca destinada ao fracasso, "Os Detetives Selvagens" - assim se chama a novela - nos mostra quem sabe um terceiro modo, detetivesco em fim, de nos imaginar em nossa função: o analista como detetive selvagem, quase um performer ativamente comprometido em sua clínica. Aqui sim o desconcerto encontra seu lugar, pois o analista transforma seu próprio desconcerto em exercício desconcertante, enquanto se oferece como refúgio e espaço de construção de respostas provisórias, mutantes, frente ao mesmo. O terceiro modelo, mais que da neutralidade analítica, é tributário da função desejo do analista, destacada por Lacan e de inusitado valor em uma clínica como a dos nossos dias.

\footnotetext{
${ }^{3}$ NT: xereta

${ }^{4}$ Claro que este modo de ouvir, como todos, pode transformar-se - mudança na posição subjetiva mediante - como acontece com o personagem encarnado pelo espião em $A$ vida dos outros...
} 
Detetive selvagem aqui não equivale a analista selvagem. A qualidade de "selvagem" me serve para pensar em um analista orientado para um futuro onde já não há certezas, onde os grandes relatos que davam coesão ao imaginário social têm caído, onde a figura do pai, para o bem ou para o mal, tem se depreciado inevitavelmente, onde a liquidez substituiu a solidez. Quer dizer, esta figura me serve para pensar no analista em um contexto epocal radicalmente diferente do que o viu nascer, para projeta-lo e torná-lo viável.

Essa figura do analista como detetive selvagem não habita a cena do crime impoluta que os personagens de Poe e Agatha Christie exploravam com uma mente que funcionava como um bisturi. Tampouco é o "private eye", o investigador difícil de diferenciar dos meliantes com os quais se envolve, que Marlowe ou Chandler inventaram. Se o primeiro modelo se refere a um enquadre analítico asséptico e alheio a toda contaminação do social; o segundo modelo remete mais ao cercado com fitas amarelas usadas pelos investigadores forenses para delimitar uma cena do crime na qual quem investiga é sempre suspeito e se confunde com quem é investigado, onde as transferências são sempre recíprocas. Ambos os modos correspondem a formas distintas - isoláveis em sua diacronia, presentes em sua sincronia de pensar o dispositivo analítico. A terceira modalidade, em contrapartida, anseia inventar coordenadas analíticas onde não as há; sua escuta em tempos incertos busca fazer nascer um espaço de análise onde a época não o garante nem o favorece.

\section{Variantes do desconcerto}

Se pensarmos na tríade freudiana de inibição, sintoma e angústia, os dois primeiros modos de escuta que resgato correspondem ao vértice do sintoma. Um analista que funciona como um detetive, em qualquer das duas vertentes que pontuo, diga-se como Sherlock Holmes ou Philip Marlowe, não faz mais que ampliar, com variantes, uma leitura sintomática da realidade. O paradigma em jogo é indiciário e tem profundidade, ao tom do Zeitgeist no qual a psicanálise viu a luz.

Entretanto, o terceiro modo de escuta, o do analista como detetive selvagem, sem renunciar a ler sintomas, vai mais além, buscando seu lugar em uma época que privilegia mais a viagem vertiginosa pelas superfícies do que a exploração das profundezas. Já que falamos de uma análise em movimento, trata-se de um deslocamento progressivo que parte em um extremo da inibição para se aproximar tangenciando, na outra extremidade, a angústia. Em um pequeno 
quadro inventado por Lacan ${ }^{5}$, ao começar o movimento - e se trata de que enquanto analistas, nos movimentemos - aparece o turvamento, quer dizer, o desconcerto.

Não há possibilidade hoje em dia - se é que desejamos que a psicanálise continue sendo contemporânea - que pensa-la no polo oposto da inibição, ou seja, em movimento. Só na aparência a análise é uma prática sedentária: analisar-se é empreender uma viagem e um divã bem pode - deve - transformar-se em tapete voador. É importante saber em que medida o desconcerto do analista o ajudará ou não a conduzir a cura, a desempenhar-se como guia comprometido nessa exploração.

Enigma, mistério e desconcerto giram em torno de um afeto fundamental, o da angústia, norte magnético na orientação da nossa prática. Quando as respostas fantasmáticas de nossos pacientes cambaleiam, aparece a angústia que possibilita uma análise. Como analistas não estamos isentos de padecer nós mesmos a angústia, e quem sabe às vezes não haja problema que assim o seja. Pois a angústia concretamente não é outra coisa senão a constatação de que o analista é, sabendo-o ou não, um funâmbulo (Lacan) que trabalha sem rede. A angústia é essa consciência transitória que, no caso de instalar-se, pode impedir nossa possibilidade de escuta. O mesmo ocorre com sua sucedânea: a confusão, resposta do analista ao momento em que se desequilibram suas certezas.

Quase imperceptivelmente, passamos a considerar o afeto do desconcerto não do lado do analisante, mas do lado do analista. E aí cabe situá-lo nesta outra tríade, diferenciando o desconcerto (turbamento ${ }^{6}$ ) de outros estados afetivos adjacentes, como a surpresa (assombro), e a desorientação (confusão).

O movimento pode desconcertar, mas também desorientar o analista, gerar confusão. Confusão e análise constituem um par antitético e um analista se resgata quando consegue deslindar - analisar - o que o confunde. E nesse autorresgate da sua função analítica resgata seu analisante como tal. Tudo o que conspira contra a análise, seja em modalidades psicopatológicas da época ou no vai-e-vem do social, induz confusão esterilizante e analisar consiste nessa alquimia secreta que transmuta confusão em desconcerto.

Pelo contrário, a surpresa tem um efeito iluminador. Frente à tendência/tentação entrópica e adormecedora, frente a uma disciplina que tende a esquecer a invenção através da aplicação

\footnotetext{
${ }^{5}$ Aí dispõe escalonadamente os três termos heteróclitos de inibição, sintoma e angústia. (O Seminário de Jacques Lacan, Livro 10, A Angústia, classe do 14 de novembro de 1962, Paidós, Bs As, 2006, p.22)

6 “o turbamento é o transtorno..., o transtornar-se mais profundamente na dimensão do movimento" Lacan, íd., p.21-22
} 
de um saber, frente à domesticação do inesperado que toda prática profissional propicia, a surpresa refresca. Trate-se da aparição de uma lembrança inesperada ou um insight que inaugure uma nova posição para o analisante, ou da descoberta de novos fatos clínicos, do redescobrimento singular de um velho conceito teórico ou do surgimento de uma interpretação não calculada para o analista, a surpresa é fértil para a análise. Foi desde a surpresa que Freud tropeçou tanto com a sexualidade quanto com a suposta fabulação de suas histéricas, foi desde a surpresa que a transferência surpreendeu Breuer. Esse assombro originário, destinado a degradar-se e desaparecer, é algo a resgatar diariamente (embora só aconteça em contadas oportunidades). Se a análise converte confusão em desconcerto, quem sabe a surpresa seja sua consequência pontual, tão fértil como inesperada, que nos leva sempre um pouco mais longe. Nesse caminho, uma tensão que invalida se converte em fértil mal estar, inclusive nesses momentos de felicidade que justificam ao analista em seu ofício.

Recuperar o desconcerto implica resgatar-nos como analistas. Pois desconcertar também é decompor em partes ${ }^{7}$, quer dizer desmontar, quer dizer analisar. Nesse sentido, analisar é desconcertar.

Se concertar implica produzir um acordo, desconcertar implica explodi-lo. Uma análise avança assim, através de inversões dialéticas (Lacan) nas quais quem se analisa é desconcertado e implicado pela intervenção de seu analista para então, momentos depois, construir um consenso tranquilizador. É nesse momento que uma nova intervenção tem que se resgatar da mortífera e complacente pax analytica para jogar as associações do paciente em outro lugar, desconcertando-o. Em um processo que se repetirá uma e outra vez, até que reste pouco a se dizer.

Assim o desconcerto do analista, operacionalizado no sentido da cura, impede todo concerto coagulado, acoplamento imaginariamente perfeito entre ambos os membros do chamado par analítico, que de par tem pouco.

Mas, realmente está em nossas mãos produzir voluntariamente desconcerto? Pareceria que tão pouco como produzir mal entendidos ou produzir angústia. O que o analista consegue na maioria das vezes, com sorte, é abrigar o desconcerto que faz parte da estrutura da situação analítica e que o diálogo cotidiano e os supostos acordos e convenções da vida social dissimulam.

\footnotetext{
${ }^{7}$ Decomposição das partes de um corpo ou de uma máquina (Dicionário da RAE).
} 


\section{A psicanálise como guia de perplexos}

Recapitulando e parafraseando John Berger e seus "modos de ver", poderíamos pensar então em diferentes modos de ouvir:

Ao modo de quem desvenda enigmas através de ferramentas analíticas, como o neutro Sherlock Holmes.

$\mathrm{Ou}$ ao modo de quem combate enquanto escuta desde o mesmo lodo onde acontecem as coisas, como os detetives das novelas de mistério, da série negra, presos em uma voragem de transferências recíprocas.

Ou ao modo de uma escuta espiã, intrigante, que reduz a ética da análise a uma caricatura funesta.

Ou em um modo, em boa medida a ser construído, que resgate o melhor da tradição, o que distingue a escuta inédita do analista e ao mesmo tempo a projeta, não sem certo anacronismo, nem certa dose de coragem e intuição, ao porvir, tornando os analistas verdadeiros detetives selvagens.

Ainda os diferenciando, também o enigma e o mistério são formas do desconcerto. A figura do analista detetive tipo Sherlock Holmes procura liquidá-los, enquanto a figura do analista tributária de Philip Marlowe convive com eles. A figura do analista como detetive selvagem se propõe, por sua vez, propiciá-los.

De que maneira? Fundamentalmente duas: por um lado, através da interpretação, medida mais por seus efeitos do que por suas intenções; concebida menos por seu conteúdo do que pela sua capacidade de produzir ondas (Lacan). Um momento fértil da análise é quando um analista consegue transformar seu próprio desconcerto, em uma intervenção, em uma manobra desconcertante, algo que ocorre em raras e, portanto, preciosas ocasiões. Esse é o ponto preciso em que se gesta uma interpretação analítica desde o solo fértil de uma escuta desconcertada.

Por outro lado, através de um montante de silêncio oportuno. John Cage explorou bem o modo em que o silêncio é capaz de produzir desconcerto. Com suas palavras e seus silêncios, sobre o fundo abstinente ao qual sua ética o obriga, o analista compõe sua música, esse modo de escuta inédito inventado por Freud, que - a meu ver - vale mais que qualquer uma das teorias construídas a partir daí. 
Contudo, também é verdadeiro que a análise como disciplina do desconcerto tem sentido e efetividade em um panorama onde certa tranquilidade - certo concerto - tem lugar. Nestes tempos convulsionados, em nossos incertos e vapulados países periféricos nos quais o desconcerto pareceria ser norma, a potencia desconcertante da escuta analítica se dilui e a demanda se inverte: em épocas de convulsão, a operatória analítica talvez devesse ser mais que nunca apaziguadora, garantir coordenadas mais que questioná-las, sustentar uma ficção de continuidade e acordo que mitigue a angústia insuportável que sobrevém quando balançam todas as referências.

Se pensarmos na função do pai, em sua declamada decadência (função que não se confunde com as arrogantes prerrogativas patriarcais justamente questionadas), como não pensar em sua contraparte social, a anomia que parecera imperar em nossos países e seus efeitos subjetivos, ou melhor, diluentes de toda subjetividade. Neste ponto quem sabe tenhamos que inverter aquilo que caracteriza a um espaço analítico - o exercício do desconcerto - e convertê-lo em refúgio, em espaço familiar, onde cabe por em suspense as perguntas e contentar-se com respostas que acalmem, mesmo sabendo que são provisórias.

Nesse sentido, a análise pode deixar de lado em certos momentos - de uma cura, de um país seu afã desconcertante, e converter-se em guia de perplexos. Sabem que esse era o nome da principal obra do sábio Maimónides, um meteco judeu na corte árabe de Saladino. Nesse ponto a análise, sabidamente, se torna um dispositivo que guia e apazigua, que permite orientar-se na escuridão e ainda assim avançar, que promete referências onde toda referência parece haver se perdido.

Tradução: Dante Rovere 